\title{
Endovascular Treatment of Middle Cerebral Artery Aneurysms for 120 Nonselected Patients: A Prospective Cohort Study
}

\author{
B. Gory, A. Rouchaud, S. Saleme, F. Dalmay, R. Riva, F. Caire, and C. Mounayer
}

\begin{abstract}
BACKGROUND AND PURPOSE: Multiple technologies have developed the endovascular approach to MCA aneurysms. We assess the safety and the efficacy of a systematic endovascular approach in nonselected patients with MCA aneurysms and determine predictors of treatment outcomes.
\end{abstract}

MATERIALS AND METHODS: We analyzed data collected between January 2007 and January 2012 in a prospective clinical registry. All patients with MCA aneurysms treated by means of the endovascular approach were included. A multivariate analysis was conducted to identify predictors of complications, recanalization, and outcome.

RESULTS: A total of 120 patients with 131 MCA aneurysms were included. Seventy-nine patients (65.8\%) were treated electively and 41 (34.2\%) in the setting of subarachnoid hemorrhage. Thirty-three of 131 aneurysms (25.2\%) were treated with simple coiling, 79 aneurysms (60.3\%) with balloon-assisted coiling, and 19 aneurysms (14.5\%) with stent-assisted coiling. Complications occurred in $13.7 \%$ of patients. Stent-assisted coiling was significantly associated with more complications ( $P=.002$; OR: $4.86 ; 95 \% \mathrm{Cl}, 1.60-14.72)$. At 1 month after treatment, both the permanent morbidity ( $m R S \leq 2)$ and mortality rates were $3.3 \%$, without any significant difference according to the endovascular techniques. Mean angiographic follow-up was 16.3 months. The rate of recanalization was $15.6 \%$ without a statistical difference, according to the technique. Larger aneurysms were a predictor of recanalization ( $P=.016$; OR: 1.183; 95\% Cl, 1.02-1.36). Retreatment was performed in 10 of 131 aneurysms (7.6\%).

CONCLUSIONS: Even though stent-assisted coiling significantly increases the risk of procedural complications, endovascular treatment of MCA aneurysms is safe, effective, and provides durable aneurysm closure in nonselected patients.

ABBREVIATIONS: $\mathrm{EVT}=$ endovascular treatment; $\mathrm{HH}=$ Hunt and Hess

E ndovascular treatment (EVT) of intracranial aneurysms is an established technique for both ruptured and unruptured aneurysms. ${ }^{1,2}$ Nevertheless, many institutions still use surgical clipping (rather than coiling) as the first treatment for MCA aneurysms because they are accessible, even with complex anatomic features, which is not usually considered suitable for EVT with standard coiling. ${ }^{3-5}$ In a systematic review of endovascular series of MCA aneurysms, the rates of combined permanent morbidity and mortality were $5.1 \%$ and $6.0 \%$ for unruptured and ruptured aneurysms, respectively. ${ }^{6}$ However, most of these series were highly focused on selected patients. ${ }^{7-10}$ To date, with the advent of

Received July 17, 2013; accepted after revision August 30.

From the Departments of Interventional Neuroradiology (B.G., A.R., S.S., R.R., C.M.) and Neurosurgery (F.C.), Dupuytren University Hospital, Limoges, France; and INSERM UMR-1094 (F.D.), University of Limoges, Limoges, France.

Please address correspondence to Charbel Mounayer, MD, PhD, Dupuytren University Hospital, Department of Interventional Neuroradiology, 2 Ave Martin Luther King, 87042 Cedex Limoges, France; e-mail cmounayer@hotmail.com

http://dx.doi.org/10.3174/ajnr.A3781 new endovascular tools such as balloons and stents designed specifically for the intracranial circulation, MCA aneurysms can be managed by means of the endovascular approach. However, the safety and efficacy of EVT for all patients are not well known yet.

We assess the safety and the efficacy of a systematic endovascular approach in nonselected patients with MCA aneurysms in a prospective cohort. Predictors of complications, recanalization, and clinical outcome were determined.

\section{MATERIALS AND METHODS \\ Patients}

Patients were identified by means of a prospective clinical registry of patients with intracranial aneurysms, which were treated at Dupuytren University Hospital, Limoges, France, from January 2007 to January 2012. Since January 2007, a systematic endovascular approach has been implemented in all patients with MCA aneurysms. Fusiform and dissecting aneurysms were excluded, as were aneurysms associated with brain arteriovenous malformations. 


\section{Endovascular Procedures}

All procedures were performed with the use of general anesthesia and full anticoagulation (5000 IU of heparin given as an intravenous bolus injection). Anticoagulation was aimed at keeping the activated clotting time at 2 to 3 times above the normal value. We used bare platinum coils (GDC from Boston Scientific [Natick, Massachusetts]; Trufill from Codman \& Shurtleff [Raynham, Massachusetts]; and MicroPlex from MicroVention [Tustin, California]).

In the setting of SAH, we used simple coiling or balloon-assisted techniques, considering the size of the neck and the need to protect MCA branches. We avoided the use of stents because of the risk of thrombosis. In the case of large hematomas requiring surgical evacuation, simple coiling was rapidly performed before surgery, without any aneurysm clipping.

In unruptured cases, simple coiling, double-catheter coiling, ${ }^{11}$ balloon-assisted, ${ }^{12,13}$ or stent-assisted coiling ${ }^{14}$ were used, depending on the neck size and aneurysm anatomy. In some cases of stent use, we used the balloon-assisted technique before inserting a stent because it appeared that the balloon technique obtained denser packing because of the inherent difficulty of crossing the stent struts in the first instance or in regaining access into the aneurysm. However, we considered it a stent group. In addition, in the case of simple coiling or balloon-assisted coiling for unruptured aneurysms, $250 \mathrm{mg}$ of aspirin was given intravenously during the procedure. In the case of stent-assisted coiling, patients were given dual-antiplatelet therapy before surgery, which was continued for 12 months (75-150 mg clopidogrel, $160 \mathrm{mg}$ aspirin daily).

\section{Data Collection}

We analyzed clinical and procedural data, considering patient age and sex, state of aneurysms, technique of EVT, technical complications, anatomic results, and patient evolution, 1 month after the procedure (C.M., R.R., B.G.). Technical complications were classified into thromboembolic events (clots near the neck of the aneurysm and/or in the distal branches), aneurysm rupture (extravasation of contrast media at the level of the aneurysm), and artery perforation (extravasation of contrast media at the level of artery). All technical complications were noted, whatever the clinical issue.

Angiographic images were acquired in the anteroposterior and lateral working projections before and immediately after treatment. The angiographic follow-up protocol consisted of the first angiogram performed 1-6 months after endovascular treatment and the second angiogram being performed 1 year after the first follow-up. A third angiogram was performed 2 years after the second follow-up.

\section{Data Analysis}

The location of the aneurysms was classified into 3 groups: proximal, bifurcation, and distal MCA aneurysms. ${ }^{15}$ Aneurysm dimensions were characterized by $3 \mathrm{D}$ images. The size of the aneurysm was defined on the basis of the greatest length of the aneurysmal sac. Angiographic occlusion assessment was classified by use of the simplified 3-point Raymond classification scale. ${ }^{16} \mathrm{~A}$ 2-point classification scale was also used: total occlusion (complete obliteration) and partial occlusion (residual neck or residual aneurysm). At follow-up, we considered an aneurysm recurrence when a recanalization was found in the neck of aneurysms completely occluded, regardless of how large. We also considered it as a recurrence when we observed that the neck remnant was increased in partly occluded aneurysms.

Clinical status was given at 1 month after the treatment by use of the mRS. Permanent morbidity was defined as an mRS of 3-5. If the preoperative score was 3-4, we defined permanent morbidity when it increased by 1 point.

\section{Statistical Analysis}

Statistical analysis was performed by use of the INSERM UMR1094 (F.D.), with the use of SAS version 9.3 (SAS Institute, Cary, North Carolina). Sex, side (left/right), aneurysm status (ruptured/unruptured), wide neck (neck size $\geq 4 \mathrm{~mm}$ ), and initial total occlusion rates were evaluated for statistical significance among 3 groups, by use of the Fisher exact test. Patient age, aneurysm size, neck size, and term of follow-up were compared by use of the Kruskal-Wallis $U$ test. A stepwise multivariate logistic regression analysis was performed to control for potential confounders in aneurysm characteristics and in the occurrence of technical complications. Univariate analysis was conducted to evaluate the effect of treatment technique used on recurrence. Finally, a stepwise logistic regression analysis was used to determine factors associated with angiographic recurrence. The significance threshold was set at $P=.05$.

\section{RESULTS}

\section{Patients}

One hundred twenty patients were included in this study ( 78 women and $42 \mathrm{men}$ ). The mean age was 53.2 years (range, 25-84 years), with no significant differences among the 3 groups $(P=.904)$.

Initial Hunt and Hess $(\mathrm{HH})$ grade of I was noted in 11 patients, $\mathrm{HH}$ grade of II in 10 patients, $\mathrm{HH}$ grade of III in 9 patients, $\mathrm{HH}$ grade of IV in 6 patients, and $\mathrm{HH}$ grade of $\mathrm{V}$ in 5 patients. Eleven patients had both ruptured and unruptured MCA aneurysms.

\section{Aneurysms}

One hundred thirty-one MCA aneurysms (41 ruptured, 90 unruptured) were involved. Mean aneurysm size was $6.4 \mathrm{~mm}$ (1.5-18.4 $\mathrm{mm})$ and mean neck size was $4.1 \mathrm{~mm}(0.6-10.1 \mathrm{~mm})$. Seventy (53.5\%) of these had wide necks. Sixteen aneurysms (12.2\%) were located on the main trunk of the artery (M1 segment), 112 (85.5\%) were located at the first major bifurcation (M1-M2), and 3 (2.3\%) were located beyond the major bifurcation (M2 segment). There was no significant difference of the mean size of sac and neck (Table 1).

\section{Technique of Aneurysm Treatment}

Coiling was performed in all patients with MCA aneurysms. Thirty-three aneurysms (25.2\%) were treated with simple coiling (23 single-catheter and 10 double-catheter technique; Fig 1), 79 $(60.3 \%)$ with balloon-assisted coiling (63 standard balloon, 12 round balloon, and 2 double-balloon technique) (Fig 2), and 19 $(14.5 \%)$ with self-expandable stent-assisted coiling. Stents were delivered after coiling in $47.4 \%(n=9 ; 5$ Neuroform [Stryker Neurovascular, Kalamazoo, Michigan], 3 Enterprise [Codman \& Shurtleff], 1 Wingspan [Stryker Neurovascular] stents), and before coiling in $52.6 \%(n=10)$. We used the jailing technique ( $n=$ 8 ; 6 Neuroform and 2 Solitaire AB [Covidien, Irvine, California] stents), stent-jacking technique ( $n=1 ; 1$ Solitaire $\mathrm{AB}$ stent $),{ }^{17}$ 
Table 1: Characteristics of 131 aneurysms according to modality of endovascular treatment

\begin{tabular}{|c|c|c|c|c|c|}
\hline & \multicolumn{3}{|c|}{ Aneurysms $(n=131)$} & \multirow[b]{2}{*}{$\begin{array}{l}\text { Fisher Exact } \\
\text { Test, } P\end{array}$} & \multirow[b]{2}{*}{$\begin{array}{c}\text { Kruskal-Wallis } \\
\cup \text { Test, } P\end{array}$} \\
\hline & $\begin{array}{l}\text { Simple Coiling } \\
\qquad(n=33)\end{array}$ & $\begin{array}{l}\text { Balloon-Assisted } \\
\text { Coiling }(n=79)\end{array}$ & $\begin{array}{l}\text { Stent-Assisted } \\
\text { Coiling }(n=19)\end{array}$ & & \\
\hline \multirow[t]{2}{*}{ Side, left/right } & 14/19 & $37 / 42$ & $8 / 11$ & .878 & \\
\hline & $42 \% / 58 \%$ & $47 \% / 53 \%$ & $42 \% / 58 \%$ & & \\
\hline \multirow[t]{2}{*}{ Aneurysm status, unruptured/ruptured } & $16 / 17$ & $56 / 23$ & $18 / 1$ & .002 & \\
\hline & $48 \% / 52 \%$ & $71 \% / 29 \%$ & $95 \% / 5 \%$ & & \\
\hline Aneurysm size, $\mathrm{mm}$ & $7.4 \pm 3.8$ & $5.9 \pm 3.1$ & $7.0 \pm 4.1$ & & .086 \\
\hline Neck size, $\mathrm{mm}$ & $3.9 \pm 1.4$ & $4.1 \pm 1.6$ & $5.0 \pm 1.8$ & & .052 \\
\hline \multirow[t]{2}{*}{ Wide neck $\geq 4 \mathrm{~mm}$} & 16 & 41 & 13 & .347 & \\
\hline & $51 \%$ & $66 \%$ & $84 \%$ & & \\
\hline \multirow[t]{2}{*}{ Initial total angiographic occlusion } & 26 & 66 & 17 & .569 & \\
\hline & $79 \%$ & $85 \%$ & $89 \%$ & & \\
\hline \multirow{2}{*}{$\begin{array}{l}\text { Total angiographic occlusion } \\
\text { at follow-up }\end{array}$} & 16 & 53 & 12 & .180 & \\
\hline & $48 \%$ & $67 \%$ & $63 \%$ & & \\
\hline Follow-up, mo & $13.3 \pm 9.7$ & $17.2 \pm 12.4$ & $17.1 \pm 13.3$ & & .539 \\
\hline
\end{tabular}

Note:-Numbers in parentheses are $n(\%)$ of case procedures. Data are mean \pm standard deviation.
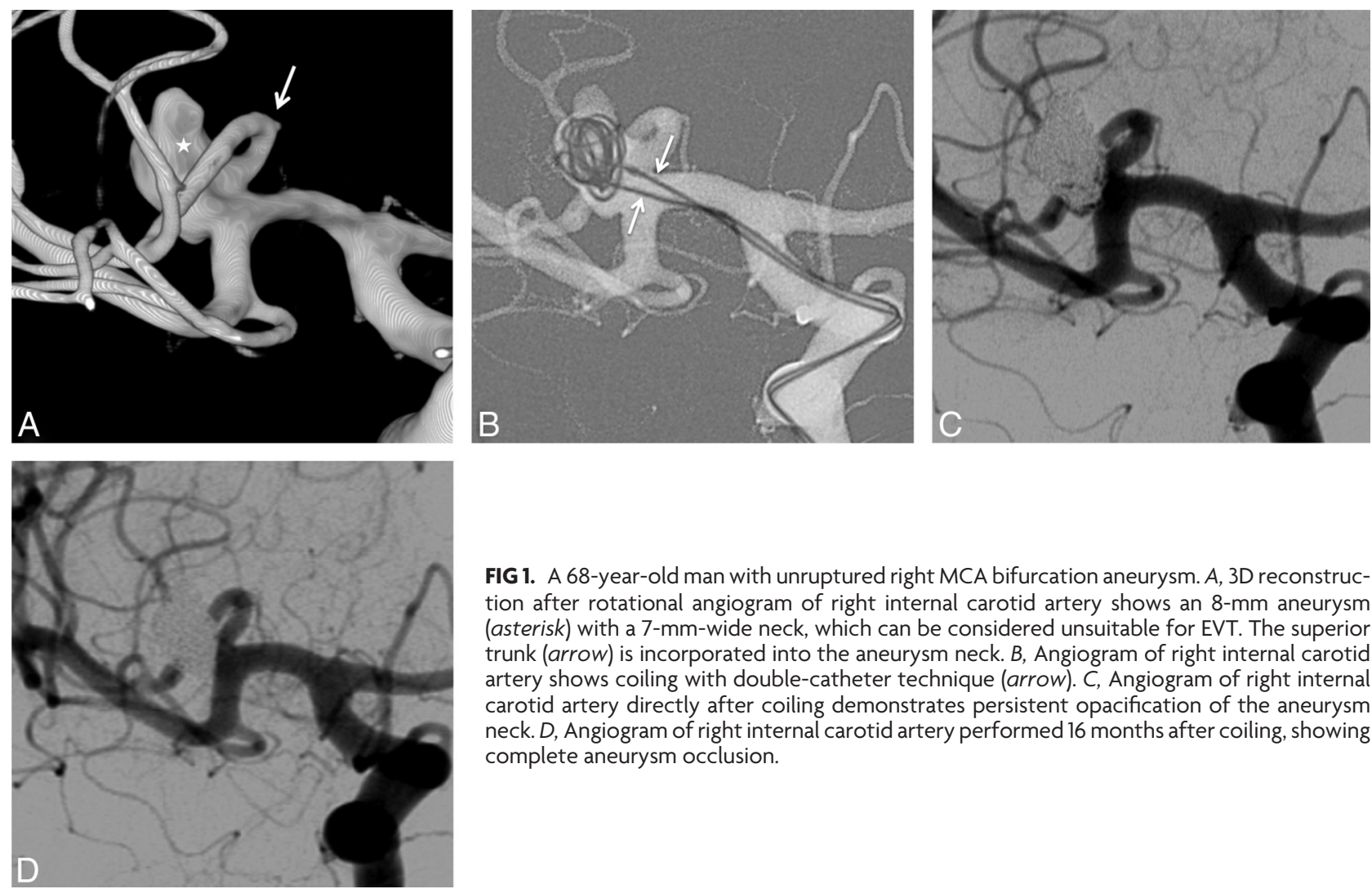

FIG 1. A 68-year-old man with unruptured right MCA bifurcation aneurysm. $A$, 3D reconstruction after rotational angiogram of right internal carotid artery shows an 8-mm aneurysm (asterisk) with a 7-mm-wide neck, which can be considered unsuitable for EVT. The superior trunk (arrow) is incorporated into the aneurysm neck. B. Angiogram of right internal carotid artery shows coiling with double-catheter technique (arrow). C, Angiogram of right internal carotid artery directly after coiling demonstrates persistent opacification of the aneurysm neck. $D$, Angiogram of right internal carotid artery performed 16 months after coiling, showing complete aneurysm occlusion.

and "Y" stent placement ( $n=1 ; 1$ Neuroform stent and 1 Enterprise stent) when stents were placed before coiling. One ruptured aneurysm ( 1 of $19,5.3 \%$ ) was treated with a rescue stent.

\section{Complications}

Table 2 reports complications during the procedure according to EVT technique. Eighteen complications (13.7\%) occurred and included 10 aneurysm sac perforations (7.6\%) (2 of 41 ruptured [4.9\%] and 8 of 90 unruptured [8.9\%] aneurysms), 2 distal parent artery perforations $(1.5 \%$ ) (1 of the 41 ruptured [2.4\%] and 1 of 90 unruptured [1.1\%] aneurysms), and 6 thromboembolic events (4.6\%) (4 of 41 ruptured [9.7\%] and 2 of 90 unruptured [2.2\%] aneurysms). There were significantly more technical complications in the stent-assisted group $(P=.005)$. In the multivariate analysis, stent assistance was the only statistically significant predictive risk factor for complications $(P=.002$; OR: 4.86; 95\% CI, 1.60-14.72; Table 3).

\section{Clinical Status}

Clinical status of patients at 1 month after treatment according to the technique is shown in Table 2 . The overall 1-month mortality rate was $3.3 \%$ ( $n=4 ; 2.5 \%$ in the unruptured group and $4.9 \%$ in the ruptured group). Three deaths were directly related to the procedure ( 2 aneurysm perforations, 1 thromboembolic event) and the other was caused by diffuse vasospasm in an initially ruptured aneurysm. The permanent morbidity rate at 1 month after the procedure was $3.3 \%$ ( $n=4 ; 3.8 \%$ in the unruptured group and $2.4 \%$ in the ruptured group). One ischemic stroke occurred secondary to focal vasospasm 

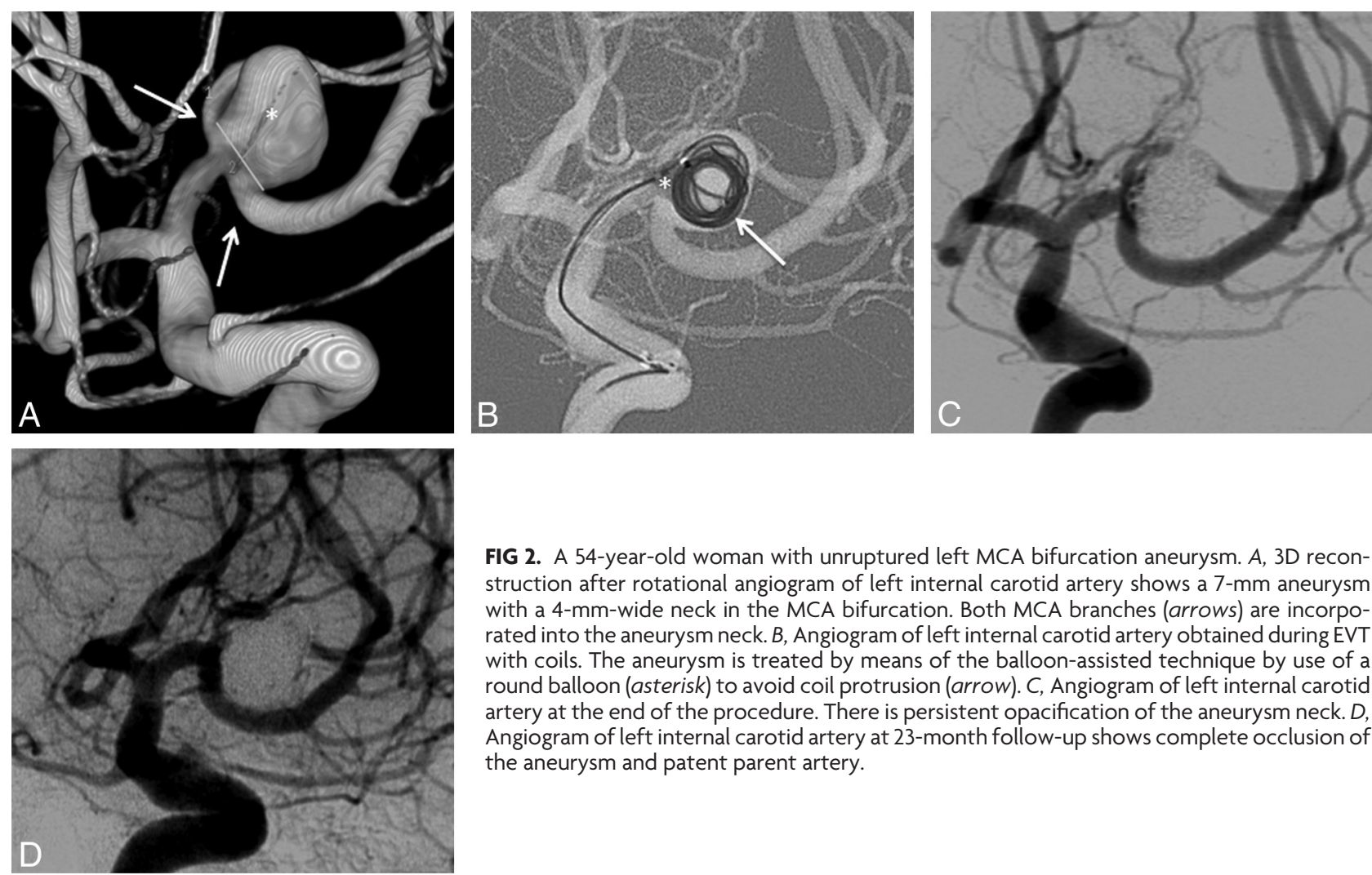

FIG 2. A 54-year-old woman with unruptured left MCA bifurcation aneurysm. A, 3D reconstruction after rotational angiogram of left internal carotid artery shows a 7-mm aneurysm with a 4-mm-wide neck in the MCA bifurcation. Both MCA branches (arrows) are incorporated into the aneurysm neck. $B$, Angiogram of left internal carotid artery obtained during EVT with coils. The aneurysm is treated by means of the balloon-assisted technique by use of a round balloon (asterisk) to avoid coil protrusion (arrow). C, Angiogram of left internal carotid artery at the end of the procedure. There is persistent opacification of the aneurysm neck. $D$, Angiogram of left internal carotid artery at 23-month follow-up shows complete occlusion of the aneurysm and patent parent artery.

Table 2: Complications according to modality of endovascular treatment

\begin{tabular}{lcccc}
\hline & $\begin{array}{c}\text { Simple } \\
\text { Coiling } \\
(\boldsymbol{n}=\mathbf{3 3 )}\end{array}$ & $\begin{array}{c}\text { Balloon- } \\
\text { Assisted } \\
\text { Coiling } \\
(\boldsymbol{n}=\mathbf{7 9})\end{array}$ & $\begin{array}{c}\text { Stent- } \\
\text { Assisted } \\
\text { Coiling } \\
(\boldsymbol{n}=19)\end{array}$ & $\begin{array}{c}\text { Fisher } \\
\text { Exact } \\
\text { Test, } \boldsymbol{P}\end{array}$ \\
\hline Hemorrhage & 1 & 7 & 4 & .642 \\
Aneurysm perforation & 1 & 5 & 4 & .048 \\
Arterial perforation & 0 & 2 & 0 & Not applicable \\
Thromboembolism & 1 & 2 & 3 & Not applicable \\
Total complications & $2(6.1 \%)$ & $9(11.4 \%)$ & $7(36.8 \%)$ & $.005^{\text {a }}$ \\
One-month morbidity & $0(0 \%)$ & $3(3.8 \%)$ & $1(5.3 \%)$ & Not applicable \\
Ruptured & 0 & 1 & 0 & \\
Unruptured & 0 & 2 & 1 & Not applicable \\
One-month mortality & $1(3.0 \%)$ & $3(3.8 \%)$ & $0(0 \%)$ & \\
Ruptured & 1 & 1 & 0 & \\
Unruptured & 0 & 2 & 0 & \\
\hline
\end{tabular}

Note:-Numbers in parentheses are $n(\%)$ of case procedures.

aThere were significantly more technical complications among the coiling group $16.1 \%$ versus $36.8 \%, P=.014)$ and the balloon-assisted group $(11.4 \%$ versus $36.8 \%, P=.018)$ than in the stent-assisted group. There was no significant difference in complication rate between coiling and balloon-assisted groups $(6.1 \%$ versus $11.4 \%, P=.605)$.

in an initially ruptured aneurysm, 2 aneurysm perforations occurred, and 1 parent vessel perforation occurred. Statistically, a significant difference was not found, whatever the EVT technique. Overall permanent morbidity and mortality rates were $7.3 \%$ and $6.3 \%$ for unruptured and ruptured aneurysms, respectively.

Thirteen of 41 ruptured aneurysms (31.7\%) had large hematomas; 8 needed surgical evacuation without clipping because the clinical status was serious. Four patients had a favorable outcome $(\mathrm{mRS} \leq 2), 2$ recorded $\mathrm{mRS}=3,1$ had $\mathrm{mRS}=4$, and the others died. The dead patient had thromboembolic complications while being treated with $2 \mathrm{mg}$ of abciximab (ReoPro). Among the other 5 patients who were treated without evacuation, 4 had a favorable outcome and the other died with severe vasospasm.
Table 3: Logistic regression analysis for complications

\begin{tabular}{|c|c|c|c|c|c|}
\hline \multirow[b]{2}{*}{ Effect } & \multicolumn{3}{|c|}{ Logistic Regression } & \multirow{2}{*}{$\begin{array}{l}\text { Fisher } \\
\text { Exact } \\
\text { Test, } P\end{array}$} & \multirow{2}{*}{$\begin{array}{l}\text { Mann- } \\
\text { Whitney } \\
U \text { Test, } P\end{array}$} \\
\hline & $P$ & OR & $95 \% \mathrm{Cl}$ & & \\
\hline Age & .62 & 0.99 & $0.95-1.02$ & & .625 \\
\hline Male & .11 & 0.35 & $0.09-1.27$ & .100 & \\
\hline Ruptured aneurysm & .57 & 1.33 & $0.48-3.69$ & .573 & \\
\hline Side & .47 & 1.42 & $0.53-3.78$ & .471 & \\
\hline Aneurysm size & .57 & 1.03 & $0.90-1.18$ & & .578 \\
\hline Neck size & .35 & 1.14 & $0.86-1.52$ & & .362 \\
\hline Coiling technique & .35 & 0.62 & $0.23-1.69$ & .351 & \\
\hline Balloon-assisted coiling & .21 & 0.54 & $0.20-1.43$ & .212 & \\
\hline Stent-assisted coiling & .005 & 4.86 & $1.60-14.72$ & .002 & \\
\hline Duration of follow-up & .85 & 1.00 & $0.96-1.05$ & & .930 \\
\hline $\begin{array}{l}\text { Initial total angiographic } \\
\text { occlusion }\end{array}$ & .59 & 0.71 & $0.21-2.41$ & .288 & \\
\hline
\end{tabular}

\section{Initial Anatomic Results}

Overall, we observed $83.2 \%$ with total occlusion, $16.0 \%$ with neck remnant, and $0.8 \%$ with sac remnant. In the simple coiling group, $78.8 \%(n=26)$ of the aneurysms were totally occluded, $18.2 \%$ $(n=6)$ had a neck remnant, and 3.0\% $(n=1)$ had a sac remnant. In the balloon group, $83.5 \%(n=66)$ of the aneurysms were totally occluded and $16.5 \%(n=13)$ had a neck remnant. In the stent group, $89.5 \%(n=17)$ of the aneurysms were totally occluded and $10.5 \%(n=2)$ had a neck remnant.

\section{(Re)Bleeding/Retreatment}

Of the 41 ruptured aneurysms treated, one (2.4\%) bled again within the first 24 hours after treatment with a simple coiling technique, though the aneurysm was totally occluded.

During the follow-up period, retreatment was performed in 10 of 131 aneurysms (7.6\%). Retreatment was performed $\leq 6$ months after the initial treatment in 7 cases and $>6$ months after treatment in 3 cases. The size of the retreated aneurysms was $\leq 10$ 
Table 4: Logistic regression analysis for factors affecting angiographic recurrence

\begin{tabular}{|c|c|c|c|c|c|}
\hline \multirow[b]{2}{*}{ Effect } & \multicolumn{3}{|c|}{ Logistic Regression } & \multirow{2}{*}{$\begin{array}{l}\text { Fisher } \\
\text { Exact } \\
\text { Test, } P\end{array}$} & \multirow{2}{*}{$\begin{array}{l}\text { Mann- } \\
\text { Whitney } \\
\text { U Test, } P\end{array}$} \\
\hline & $P$ & OR & $95 \% \mathrm{Cl}$ & & \\
\hline Age & 0.86 & 1.00 & $0.96-1.04$ & & .867 \\
\hline Male & 0.16 & 2.13 & $0.72-6.24$ & .161 & \\
\hline Ruptured aneurysm & 0.73 & 1.20 & $0.40-3.77$ & .738 & \\
\hline Side & 0.23 & 1.89 & $0.66-5.40$ & .228 & \\
\hline Aneurysm size & 0.02 & 1.18 & $1.02-1.36$ & & .016 \\
\hline Neck size & 0.55 & 1.09 & $0.81-1.48$ & & .556 \\
\hline Coiling technique & 0.77 & 1.19 & $0.35-4.09$ & .772 & \\
\hline Balloon-assisted coiling & 0.94 & 0.96 & $0.32-2.84$ & .943 & \\
\hline Stent-assisted coiling & 0.80 & 0.82 & $0.16-4.01$ & .806 & \\
\hline Duration of follow-up & 0.99 & 1.00 & $0.95-1.04$ & & .996 \\
\hline $\begin{array}{l}\text { Initial total angiographic } \\
\text { occlusion }\end{array}$ & 0.78 & 0.82 & $0.21-3.25$ & .785 & \\
\hline
\end{tabular}

$\mathrm{mm} 6$ cases and $>10 \mathrm{~mm}$ in 4 cases. Retreated aneurysms had a neck size of $<4 \mathrm{~mm}$ in 3 cases and $\geq 4$ in 7 cases. Retreated aneurysms were initially treated by coiling in 3 cases, balloon-assisted coiling in 6 cases, and stent-assisted coiling in 1 case.

\section{Anatomic Results at Follow-Up}

Mean follow-up was 16.3 months (range, 4.2-28.4 months) and the overall recurrence rate was $17(15.6 \%)$. There were 4 recurrences $(17.4 \%)$ in the simple coiling group, $11(15.5 \%)$ in the balloon-assisted group, and $2(13.3 \%)$ in the stent-assisted group. Thirteen were observed for the first 6 months and the remainder in the second year after treatment. A larger aneurysm size was significantly associated with an increased recurrence rate $(P=$ .016; OR: 1.183; 95\% CI, 1.02-1.36; Table 4).

\section{DISCUSSION}

In this study, we assessed the safety and efficacy of an endovascular approach to MCA aneurysms in nonselected patients. All patients were consecutively included, not being selected by any criteria as long as they did not have fusiform or dissecting aneurysms, which minimized the effect of confounders and patient-selection bias. Even though MCA aneurysms are often considered unsuitable for endovascular therapy because of a wide neck and/or branches arising from the neck, these are now accessible because of the development of devices such as balloons and self-expanding stents. During the same time that the present study was conducted, no patients with MCA aneurysms were treated by clipping in our center. Only if the patient had symptomatic large intracerebral hematoma was a surgical evacuation conducted right after coiling. According to our results, endovascular treatment was feasible in all cases regardless of the aneurysm geometry or clinical status.

Complications occurred in $13.7 \%$ of patients in this series, causing death or permanent morbidity in $6.6 \%$, which confirms the safety of the endovascular approach for treatment of MCA aneurysms. Of note, we used the number of patients involved as our denominator to figure out morbidity-mortality. The morbidity and mortality rates in our series are similar to those in previous EVT studies in selected cases such as the results by Suzuki et $\mathrm{al}^{8}$ and Vendrell et al. ${ }^{9}$ Meanwhile, morbidity-mortality of surgical clipping of MCA aneurysms is largely variable, ranging from $1.8-13.6 \% .^{3-5,15}$ Recently the UCSF neurosurgical group reported a $5.3 \%$ mortality rate and a $4.6 \%$ permanent morbidity rate after managing $631 \mathrm{MCA}$ aneurysms (51.9\% ruptured aneurysms) in 543 patients. ${ }^{3}$ Its combined morbidity and mortality rate was $9.9 \%$, which seems less safe than EVT outcome.
However, this UCSF study probably included high-risk aneurysms, as did our study (the size of the aneurysm was $\geq 10 \mathrm{~mm}$ in $13.7 \%$ of cases, and 53.5\% of aneurysms had wide necks; illustrated in Figs 1 and 2). In our series, the percentage of complications was slightly but not significantly higher in the ruptured aneurysms group (17.1\%) versus the unruptured aneurysms group (12.2\%), as previously reported in a systematic review of MCA aneurysms. ${ }^{6}$ The UCSF group also reported more complications in the case of ruptured aneurysms (8.5\% versus $4.9 \%$ ).

At 1 month, our global mortality and permanent morbidity rates were not negligible $(7.3 \%$ and $6.3 \%$ for unruptured and ruptured aneurysms, respectively). Comparing our series of patients harboring ruptured and unruptured aneurysms who were treated by EVT with a series of patients treated by clipping, shortterm mortality and morbidity are not higher. In a series by a UCSF group, at mean follow-up of 30 months, overall mortality and permanent morbidity (mRS $\leq 2$ ) were $7.6 \%$ and $29.3 \%$ for unruptured and ruptured aneurysms, respectively. ${ }^{6}$ Twenty-two percent were poor-grade patients ( $\mathrm{HH}$ grades IV and $\mathrm{V}$ ) in the UCSF study, whereas $27 \%$ were poor-grade in our study.

Several endovascular techniques are currently used, including double catheter, ${ }^{11}$ balloon-assisted coiling, ${ }^{12,13}$ and stent-assisted coiling techniques. ${ }^{14,17}$ We used the balloon-assisted coiling technique in many cases $(60.3 \%)$ without any significant increased complication rate compared with simple coiling, as reported. ${ }^{18}$ Interestingly, our study shows that stent placement highly increases a risk of complication compared with other EVT techniques. Moreover, in logistic regression, the odds of developing complications were 4.8 times greater when stents were used. The use of antiplatelet therapy is known to increase the risk of hemorrhagic complications. ${ }^{14,19}$ In a survey of the literature that included 1517 patients treated with stents, Shapiro et $\mathrm{al}^{19}$ found a procedural complication in $19 \%$ of patients, which is lower compared with our series $(36.8 \%)$. Our high complication rate could be related to MCA location, which is more likely to associate with procedural complications in stent-assisted coiling, as recently outlined by Chalouhi et $\mathrm{al}^{20}$ after stent-assisted coiling of 508 intracranial aneurysms. We did not find any significant difference between ruptured and unruptured aneurysms. Improvement in stent technology is warranted to diminish complications and improve the safety of endovascular technology.

In the setting of SAH, the aim of treatment is not an optimal sac occlusion, but its rapid protection. If needed, a complementary treatment will be applied later. In our study, approximately $30 \%$ of ruptured aneurysms were related to huge hematomas, 8 needed surgery, and the other patients had favorable outcome. This result suggests that MCA ruptured aneurysms with hematomas can be safely managed without clipping. At this time, antiplatelet therapy is undesirable because of the potential need for a ventriculostomy or craniostomy. For these reasons, stent placement is generally avoided in acutely ruptured aneurysms because its safety is less favorable in ruptured aneurysms. In a systematic review that included 339 patients, Bodily et $\mathrm{al}^{21}$ found clinically significant intracranial hemorrhagic and thromboembolic complications in $8 \%$ and $6 \%$, respectively.

Complete aneurysm occlusion was achieved in most cases (83.2\%); this suggests that EVT could be an effective treatment for all 
MCA aneurysms. It also showed that EVT is a durable treatment with a low rate of angiographic recurrence at medium-term follow-up. This recurrence rate (15.6\%) showed similar results to those of studies of MCA aneurysms in selected patients (13.0-38.3\%). ${ }^{6}$ This finding could be explained by the frequent use of balloon-assisted coiling, which appears to increase the long-term anatomic results compared standard coiling. ${ }^{18}$ Our study has identified aneurysm size as the only significant risk factor for recurrence, as previously shown. ${ }^{14,16}$ Though the rate of aneurysm recurrence appears to be low after surgical clipping, it is difficult to compare a recurrence risk of EVT with surgical clipping because only a few surgical series report long-term follow-up. There was an increased risk of recurrent bleeding from a coiled aneurysm compared with a clipped aneurysm, but the risks were very low. ${ }^{22,23}$ In long-term follow-up of the International Subarachnoid Aneurysm Trial patients, 10 rebleedings occurred in the coiled group and 3 in the clipping group. ${ }^{23}$ In our series, one ruptured aneurysm bled again within the first 24 hours after treatment (2.4\%) on 16.3 (mean) months of follow-up. Results from the Cerebral Aneurysm Rerupture After Treatment were similar with a 1.8\% risk of re-rupture in the first year. ${ }^{24}$

Despite widespread opinion, endovascular therapy should be the treatment of choice for MCA aneurysms, supporting the conclusion reached in the position statement of the American Association of Neurologic Surgeons and American Society of Neuroradiology. ${ }^{25}$

\section{Limitations}

Our study is limited by its small sample size and the absence of randomization between study groups. The results reflect a systematic and routine endovascular approach in an experienced neurovascular center. Because the duration of follow-up was short, the incidence of recurrence probably has been underestimated. However, in most intracranial aneurysms adequately occluded 6 months after coiling, prolonged imaging follow-up within the first 5-10 years after coiling does not seem beneficial in terms of detecting reopened aneurysms that need retreatment. ${ }^{26}$

\section{CONCLUSIONS}

Even though stent-assisted coiling significantly increases the risk of procedural complications, endovascular treatment of all MCA aneurysms is safe, effective, and provides durable aneurysm closure.

\section{REFERENCES}

1. Molyneux A, Kerr R, Stratton I, et al. International Subarachnoid Aneurysm Trial (ISAT) Collaborative group: International Subarachnoid Aneurysm Trial (ISAT) of neurosurgical clipping versus endovascular coiling in 2143 patients with ruptured intracranial aneurysms - a randomized trial. Lancet 2002;360:1267-74

2. Spetzler RF, McDougall CG, Albuquerque FC, et al. The Barrow Ruptured Aneurysm Trial: 3-year results. J Neurosurg 2013;119:146-57

3. Rodríguez-Hernández A, Sughrue ME, Akhavan S, et al. Current management of middle cerebral artery aneurysms: surgical results with a "clip first" policy. Neurosurgery 2013;72:415-27

4. Choi SW, Ahn JS, Park JC, et al. Surgical treatment of unruptured intracranial middle cerebral artery aneurysms: angiographic and clinical outcomes in 143 aneurysms. J Cerebrovasc Endovasc Neurosurg 2012;14:289-94

5. Elsharkawy A, Lehecka M, Niemelä $M$, et al. A new more accurate classification of MCA aneurysms: CT angiographic study of 1009 consecutive cases with 1309 MCA aneurysms. Neurosurgery 2013;73:94-102

6. Brinjikji W, Lanzino G, Cloft HJ, et al. Endovascular treatment of middle cerebral artery aneurysms: a systematic review and singlecenter series. Neurosurgery 2011;68:397-402

7. Bracard S, Abdel-Kerim A, Thuillier L, et al. Endovascular coil occlusion of 152 middle cerebral artery aneurysms: initial and midterm angiographic and clinical results. J Neurosurg 2010;112:703-08

8. Suzuki S, Tateshima S, Jahan R, et al. Endovascular treatment of middle cerebral artery aneurysms with detachable coils: angiographic and clinical outcomes in 115 consecutive patients. Neurosurgery 2009;64:876-89

9. Vendrell JF, Menjot N, Costalat V, et al. Endovascular treatment of 174 middle cerebral artery aneurysms: clinical outcome and radiologic results at long-term follow-up. Radiology 2009;253:191-98

10. Iijima A, Piotin M, Mounayer C, et al. Endovascular treatment with coils of 149 middle cerebral artery berry aneurysms. Radiology 2005;237:611-19

11. Kwon OK, Kim SH, Kwon BJ, et al. Endovascular treatment of widenecked aneurysms by using two microcatheters: techniques and outcomes in 25 patients. AJNR Am J Neuroradiol 2005;26:894-90

12. Moret J, Cognard C, Weill A, et al. The "remodeling technique" in the treatment of wide neck intracranial aneurysms. Intervent $\mathrm{Neu}$ roradiol 1997;3:21-35

13. Gory B, Kessler I, Seizem Nekiri G, et al. Initial experience of intracranial aneurysm embolization using the balloon remodeling technique with Scepter C, a new double-lumen balloon. Interv Neuroradiol 2012;18:284-87

14. Piotin M, Blanc R, Spelle L, et al. Stent-assisted coiling of intracranial aneurysms: clinical and angiographic results in 216 consecutive aneurysms. Stroke 2010;41:110-15

15. Rinne J, Hemesniemi J, Niskanen M, et al. Analysis of 561 patients with 690 middle cerebral artery aneurysms: anatomic and clinical features as correlated to management outcome. Neurosurgery 1996;38:2-11

16. Raymond J, Guilbert F, Weill A, et al. Long-term angiographic recurrences after selective endovascular treatment of aneurysms with detachable coils. Stroke 2003;34:1398-403

17. de Paula Lucas C, Piotin M, Spelle L, et al. Stent-jack technique in stentassisted coiling of wide-neck aneurysms. Neurosurgery 2008;62:414-17

18. Pierot L, Cognard C, Anxionnat R, Ricolfi F; CLARITY Investigators. Remodeling technique for endovascular treatment of ruptured intracranial aneurysms had a higher rate of adequate postoperative occlusion than did conventional coil embolization with comparable safety. Radiology 2011;258:546-53

19. Shapiro M, Becske T, Sahlein D, et al. Stent-supported aneurysm coiling: a literature survey of treatment and follow-up. AJNR Am J Neuroradiol 2012;33:159-63

20. Chalouhi N, Jabbour P, Singhal S, et al. Stent-assisted coiling of intracranial aneurysms: predictors of complications, recanalization, and outcome in $\mathbf{5 0 8}$ cases. Stroke 2013;44:1348-53

21. Bodily KD, Cloft HJ, Lanzino G, et al. Stent-assisted coiling in acutely ruptured intracranial aneurysms: a qualitative, systematic review of the literature. AJNR Am J Neuroradiol 2011;32:1232-36

22. Tsutsumi $\mathrm{K}$, Ueki $\mathrm{K}$, Morita A, et al. Risk of aneurysm recurrence in patients with clipped cerebral aneurysms: results of long-term follow-up angiography. Stroke 2001;32:1191-94

23. Molyneux AJ, Kerr RSC, Birks J, et al. Risk of recurrent subarachnoid haemorrhage, death and the standardised mortality ratios after clipping or coiling of an intracranial aneurysm the International Subarachnoid Aneurysm Trial (ISAT): long-term follow-up. Lancet Neurol 2009;8:427-33

24. Johnston SC, Dowd CF, Higashida RT, et al. Predictors of rehemorrhage after treatment of ruptured intracranial aneurysms: the Cerebral Aneurysm Rerupture After Treatment (CARAT) study. Stroke 2008;39:120-25

25. Harbaugh RE, Heros RC, Hadley MN. AANS position statement on the International Subarachnoid Aneurysm Trial (ISAT). Lancet 2003;361:783-84

26. Ferns SP, Sprengers ME, van Rooij WJ, et al. Late reopening of adequately coiled intracranial aneurysms: frequency and risk factors in 400 patients with 440 aneurysms. Stroke 2011;42:1331-37 